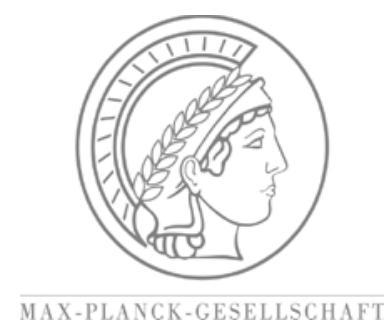

\# 1018

Inter-firm rivalry and firm growth: Is there any evidence of direct competition between firms?

by

Alex Coad Mercedes Teruel

The Papers on Economics and Evolution are edited by the Evolutionary Economics Group, MPI Jena. For editorial correspondence, please contact: evopapers@econ.mpg.de

ISSN 1430-4716
Max Planck Institute of Economics Evolutionary Economics Group Kahlaische Str. 10 07745 Jena, Germany Fax: ++49-3641-686868

(C) by the author 


\title{
Inter-firm rivalry and firm growth: Is there any evidence of direct competition between firms? *
}

\author{
Alex Coad $^{a} \quad$ Mercedes Teruel $^{b}$
}

December 13, 2010

a Max Planck Institute of Economics, Evolutionary Economics group, Kahlaische Strasse 10, Jena 07745, Germany.

$b$ Departament d'Economia, Universitat Rovira i Virgili, Avda. Universitat 1, Reus 43204, Spain.

\begin{abstract}
Inter-firm competition has received much attention in the theoretical literature, but recent empirical work suggests that the growth rates of rival firms are uncorrelated, and that firm growth can be taken as an essentially independent process. We begin by investigating the correlations of the growth rates of competing firms (i.e. the largest and second-largest firms in the same industry) and observe that, surprisingly, the growth of these firms can be taken as independent. Nevertheless, peer-effect regressions, that take into account the simultaneous interdependence of growth rates of rival firms, are able to identify significant negative effects of rivals' growth on a firm's growth.
\end{abstract}

JEL codes: L25

Keywords: Competition, Firm growth, Peer effects econometrics

${ }^{*}$ We are very much indebted to Harald Oberhofer and Michael Pfaffermayr for invaluable help with the peer-effects econometrics, and also to Rob Byrne, Tim Hazledine, Mike Hopkins, Mikael Juselius, Alessio Moneta, David Storey, Nick von Tunzelmann, and participants at the Ratio Institute workshop on "Understanding firm growth" (Stockholm, August 12-13th 2010), the ZEW conference on "Quantitative analysis in competition assessments" (Mannheim, October 21-22 2010) and seminar participants at the Max Planck Institute of Economics (Jena, Germany) and at Alcalá de Henares for helpful discussions. This paper is part of the research done with the financial support of the Spanish Ministry of Innovation and Science in the project ECO200908735 and the Consolidated Group of Research 2009-SGR-907. The usual disclaimer applies. All remaining errors are ours alone. 
"The businessman feels himself to be in a competitive situation even if he is alone in his field or if, though not alone, he holds a position such that investigating government experts fail to see any effective competition between him and any other firms in the same or a neighboring field and in consequence conclude that his talk, under examination, about his competitive sorrows is all make-believe."

Schumpeter (1942, p. 85)

\section{Introduction}

A central concept in economic development is the issue of inter-firm competition. For example, John Stuart Mill wrote that "only through the principle of competition has political economy any pretension to the character of a science" (Mill, 1984, p. 147). For a subject of its importance, therefore, inter-firm competition seems to be poorly understood and relatively under-researched. "Competition seems very well in practice, but it is not so clear how it works in theory," according to Vickers (1995, p. 1). Unfortunately, though, we suggest that inter-firm competition does not seem to be well-understood even in practice. Some recent empirical investigations into inter-firm competition have failed to find strong evidence of inter-firm competition, and suggest that firm growth can be modelled as an independent process. At the same time, however, management scholars continue to emphasize the crucial role of inter-firm competition, and have even coined new expressions such as 'hypercompetition' (see e.g. D'Aveni, 1994; Wiggins and Ruefli, 2005). Furthermore, the phenomenon of 'industrial espionage' certainly indicates that some firms consider that competitive pressure is not only a vague industry-wide force but that there are strong sources of direct competition coming from specific rivals (for a survey of industrial espionage, see Crane (2005)).

The aim of this paper is to complement the sparse literature by providing new empirical evidence on the matter. We begin with investigations of direct competition at the firm-dyad level of analysis (following Sutton (2007)), focusing on the correlations of growth rates of the largest versus second largest firms in specific sectors. Afterwards, we relate the growth of firms to the growth of rivals 
in the same sector, by taking advantage of recent developments in peer-effects econometrics.

The structure of the paper is the following. The next section briefly summarizes the relevant literature. Section 3 presents the database and Sections 4 and 5 contain the analysis. In Section 4 we focus on correlations between the largest and second largest firm in each sector, while Section 5 contains our regression results. The final section (Section 6) draws the conclusions, discussing the results and suggesting future research directions.

\section{Literature review}

\subsection{Theoretical literature}

Theoretical models of inter-firm competition have generally suggested that the growth of one firm is negatively correlated with the growth of its rival. "[C]ompetitors are typically seen as being in an ongoing, zero-sum battle with each other for customers, resources, and other rewards" (Crane, 2005, p234). For example, the 'islands' models of firm growth (Ijiri and Simon, 1977; Sutton, 1998; Bottazzi and Secchi, 2006) hold that firms compete for a limited number of growth opportunities. The introduction of game theory into the industrial organization literature has had the effect of further emphasizing the importance of considerations of competitive interactions between firms. ${ }^{1}$ By way of an illustration, consider the case of the reaction of incumbents to the entry of new firms. The game-theoretic literature frames this situation as a one-on-one strategic game whereby entrants take market share from incumbents, and incumbents make strategic investments in capacity to deter potential entrants from entering (see e.g. Salop (1979) and Dixit (1980)). This vision of the relationship between incumbents and entrants is not entirely realistic, however (Geroski, 1995). In reality, entrants are often far too small to be of any threat, their growth is too slow, their exit hazard too high, and

\footnotetext{
${ }^{1}$ For example, Carl Shapiro's confidently-titled survey article, 'The theory of business strategy' (Shapiro, 1989), is little more than a survey of applications of game-theoretic interactions between two players in the field of industrial organization.
} 
their arrival is too erratic. Furthermore, in the unlikely event that incumbents are genuinely concerned about defending their market share from entrants, the available evidence suggests that they are unlikely to do so by investing in additional capacity, but rather through the use of strategies such as advertising or licensing deals (Geroski, 1995). As such, some predictions emerging from the theoretical literature do not closely correspond to the actual workings of the economy.

More recently, theoretical contributions on the topic of inter-firm competition have emphasized that competitive behaviour might be dampened by multi-market contact between rivals, and the threat of retaliation (Evans and Kessides, 1994; Baum and Korn, 1996). Inter-firm competition may also be dampened if one considers that the opportunity sets available to growing firms are limited by the idiosyncratic nature of a firm's existing resource configurations, managerial perception of the attractiveness of different growth strategies, and also different degrees of managerial creativity and audacity (Penrose, 1959).

To complicate things further, it has also been suggested in the management literature that rival firms should simultaneously compete and cooperate with each other (Hamel et al., 1989; Bengtsson and Kock, 2000). There are indeed many ways in which one firm may benefit from the growth of a supposed rival firm. This could occur, for example, if there is some complementary nature of the goods produced, if there are spillovers through generic aspects of advertising or lobbying, or if firms benefit from a better negotiating position with suppliers and distributors, and so on. Rival firms can also benefit from each other's successes by imitating each other. $^{2}$

As a result, theoretical work does not yield very clear predictions for expected inter-firm competitive dynamics (in terms of the growth rates of rivals), and it seems that empirical work can help to elucidate this matter.

\footnotetext{
${ }^{2} \mathrm{~A}$ vivid illustration of the importance of imitation is furnished in the example of Wal-Mart: "other chain retailers have either explicitly emulated Wal-Mart or, more broadly, changed their practices in ways that reflect Wal-Mart's influence: Target's vice chairman is quoted as saying that Target is 'the world's premier student of Wal-Mart"' (Basker, 2007, p. 191).
} 


\subsection{Empirical literature}

The early empirical research on inter-firm competition often measured competition as an industry-wide pressure (of unspecified origin), rather than a competitive pressure emanating from any single competitor. In this early literature, competition was usually measured in terms of industry concentration, or rents obtained by incumbents. However, it has been shown that these variables are poor indicators of actual inter-firm competition (Boone et al., 2007). As a result, other measures of inter-firm competition have been investigated, such as questionnaire responses on perceived competition (e.g. Nickell (1996)), import penetration (e.g. Haskel et al. (2007); Kato and Honjo (2009)) and the 'profit elasticity' indicator used in Boone et al. (2007).

While we acknowledge that there are difficulties in measuring competition, nonetheless we argue that efforts should be made to measure competition bearing in mind the importance attributed to this topic. Empirical investigations into the matter have often failed to find any significant statistical evidence of inter-firm competition, however. Storey (1994, pp. 144, 152) provides a survey of 4 empirical papers and observes that none of these four papers can find any statistically significant impact of competition on firm growth. More recently, Geroski and Gugler (2004) consider the impact of the growth of rival firms on a firm's employment growth, using a database on several thousand of the largest firms in 14 European countries. ${ }^{3}$ In their main regression results (see their Table 2) they are unable to detect any significant effect of rival's growth on firm growth, although they do find a significant negative effect in specific industries (i.e. differentiated good industries and advertising intensive industries).

Empirical work focusing on specific, narrowly-defined markets has in some cases been able to identify competitive interactions between firms. In the airline industry, Goolsbee and Syverson (2008) identify a significant effect of threat of entry on incumbent price levels, where threat of entry on an airline route A-B is measured relative to the time when Southwest Airlines operates from airports A and $\mathrm{B}$ (but not from A to B). In the pharmaceutical industry, there is a sudden

\footnotetext{
${ }^{3}$ Rival firms are defined as other firms in the same 3-digit industry.
} 
increase in competitive pressure (including the threat of entry even if no entry actually occurs) when a patent expires. In this situation, empirical work focusing on the prices of individual drugs has identified significant effects of inter-firm competition (Bergman and Rudholm, 2003). However, we want to go beyond merely 'anecdotal' evidence relating to certain peculiar submarkets, and find some general properties of competition at the more aggregated firm-level.

Questionnaire evidence on subjectively-perceived competition suggests that small business managers do feel competitive pressure. Hay and Kamshad (1994) observe that intensity of competition is ranked as the most important constraint, by far, to the growth of small and medium sized firms in the UK. Similarly, Robson and Obeng (2008) report that $49.3 \%$ of entrepreneurs report "too many competing firms" as an important, or crucial limitation to these firms in achieving their objectives (see their Table 1). Nevertheless, we argue that subjective attitudes towards inter-firm competition are no substitute for objective statistical evidence on the matter. As illustrated by our opening quote, subjectively-perceived competitive pressure may plague the imaginations of businessmen even if they are alone in their field.

An interesting contribution to the empirical literature can be found in Sutton (2007). Sutton analyzes the dynamics of market shares of leading Japanese firms. While many studies view 'competitive pressure' as a rather vague, broadly-defined, industry-wide variable affecting all firms but originating from no individual firm, Sutton looks for evidence of direct competition between specific firms. Given that market shares add to unity by construction, shocks to different firms market shares can be expected to be interdependent. It is rather surprising, therefore, to see that the changes in market share of the first and second largest firms in any industry are, in all but a few exceptional circumstances, ${ }^{4}$ uncorrelated. An implication of this finding is that the growth of (rival) firms can be taken as an independent process. For example, Sutton uses this finding to justify his model of independent shocks.

\footnotetext{
${ }^{4}$ That is, when the combined market share of these two firms is greater than $80 \%$.
} 


\subsection{The locus of competition}

Empirical investigations into inter-firm competition should consider where evidence of competition is most likely to be found. For example, are competitive forces stronger for small firms or large firms?

Small firms are often too small to avoid direct competition, and tend to thrive in specific niches or 'interstices' (Penrose, 1959). Wiklund (2007) also writes that small firms tend to avoid taking a competitive stance vis-à-vis their rivals. ${ }^{5}$ Larger firms, in contrast, are less sheltered, more visible, and their behavior is likely to have some influence on their business environment. Evidence presented in Boone et al. (2007) suggests that forces of competition are more significant for larger firms than for smaller firms. Audretsch et al. (1999) do not find any evidence of direct competition between large firms and small firms (more specifically, they observe that small-firm profits are independent of large-firm profits). In contrast, Nickell (1996) is able to detect evidence of inter-firm competition on productivity growth in his analysis of large UK manufacturing firms. Of greater relevance to our present investigation is the size disaggregation exercise in Geroski and Gugler (2004, p612), where significant (negative) effects of rival growth on firm growth can only be found for the "very large firms" category.

In this paper we take the view that inter-firm rivalry is not at its strongest between small firms, or between small and large firms, but we expect the strongest rivalry effects to be between large firms. Therefore, in our analysis we either focus on the two largest firms in specific 4-digit sectors (Section 4) or on relatively large firms with 250 employees or more (i.e. corresponding to the standard EU definition of a large firm) in Section 5.

\footnotetext{
${ }^{5}$ Wiklund (2007) writes that: "Firms grow foremost through an increase in demand in their market niche and not through taking market share from their competitors. That is, growing small firms prefer to find new market niches than fight for market share in existing markets" (p145).
} 


\section{Database}

This study uses the Spanish Mercantile Register through the System of Analysis of Iberian Balance Sheets (SABI database) compiled by Bureau van Dijk. This database offers exhaustive information from balance sheets and financial sources for a large number of firms. In our regression analysis, our main sample database focuses on large manufacturing firms with 250 or more employees in 2000 and we observe their evolution until 2006 (both years included). ${ }^{6}$ Our sample is unbalanced (entries and exits may occur during the period) and contains 579 firms in the year $2000 .^{7}$

Firm growth is measured using three different indicators: employees, sales and value added. Each indicator taken individually has its own idiosyncratic drawbacks, but in our analysis we observe that the different indicators give broadly similar results. Measuring size and growth in terms of employees avoids controversies related to the choice of deflators. Previous work has identified the migration of workers into rival firms (e.g. Franco and Filson (2006), Almeida and Kogut (1999)), which justifies our interest in employment growth. However, one problem is that the number of employees often does not change from one year to the next (i.e. growth $=0.00){ }^{8}$ Furthermore, a focus on a headcount of employees does not take into account different skill levels of a firm's employees. Alternatively, Sales and Profits can be used to measure firm growth. A drawback of these variables is that they must be deflated. Nevertheless, these are the most common variables used to measure firm size and market power (sales in particular). The variable 'Profits' (measured here as total income - operating expenditures) is also a key variable in antitrust investigations by competition authorities (Geroski and Griffith, 2004). However, we have many negative values for profits, which implies that we cannot calculate growth rates for many observations. Hence, we use value

\footnotetext{
${ }^{6}$ In keeping with previous work on this database, we have excluded two sectors due to the scarce number of firms: NACE16 (Tobacco industry) and NACE23 (Petroleum industry).

${ }^{7}$ One drawback of this database is that micro firms are not well represented. However, this is no cause for concern here given that we focus on large firms.

${ }^{8}$ We should also remark that the variable Employees is not a compulsory reporting requirement for some firms. As a consequence, we may lose some observations when analysing this variable.
} 
added, which contains information on both firm size and also relative financial performance (cf the correlation matrix in Table 2). Finally, we should mention that sales and value added have been deflated using sector-specific deflators at the four-digit level.

Unlike Sutton (2007), we focus on firm growth rather than the dynamics of market shares. Normalizing firm growth into market share growth, by dividing firm growth by industry growth, can be seen as an artificial way of introducing endogeneity and interdependence between firms, and we suggest that this is not necessary for the purposes of our present analysis. It is interesting to consider that Sutton (2007) observes that the growth of rival firms can be seen as uncorrelated, even when their growth is measured in terms of market share dynamics. We can therefore anticipate, a fortiori, that our investigations of firm growth (measured in terms of employees, sales and value added) will show that the growth of rival firms is uncorrelated.

With respect to the classification of firms to a sector, in Spain firms declare their sector of main activity (according to the NACE classification scheme) and other "secondary activities." Here, we classify firms to one sector in accordance with their main activity. Hence, we do not consider the possibility that a firm may be operating in similar or completely different sectors simultaneously. Details on the industry classification scheme can be found online. ${ }^{9}$

Table 1 shows the descriptive statistics of main variables for the years 2000 and 2006. First, the average firm size is 570 employees. Second, at the end of the period of observation we observe a slightly smaller size measured in employees and sales among smaller firms (10\%, $25 \%$ and $50 \%$ quantiles), while there is an increase of the values for the largest firms (see the $75 \%$ and $90 \%$ quantiles). Conversely, value added has increased in 2006 for firms in the smallest percentiles, while for firms belonging to the largest percentiles value added decreased during the same period.

Table 2 shows the correlation matrices for levels of employees, sales, value added

\footnotetext{
${ }^{9}$ For more information, see www.idescat.cat/Classif/Classif?TC $=5 \& \mathrm{~V} 0=1 \& \mathrm{~V} 1=1 \& \mathrm{~V} 2=3$ and www.gobcan.es/cicnt/doc/comercio/CNAE.pdf.
} 
Table 1: Descriptive statistics for Spanish manufacturing firms with 250 workers or more.

\begin{tabular}{l|cc|ccccc}
\hline \hline & Mean & SD & $10 \%$ & $25 \%$ & Median & $75 \%$ & $90 \%$ \\
\hline 2000: & $\mathbf{5 7 9}$ obs & \multicolumn{7}{c}{} \\
\hline Empl & 577 & 835 & 268 & 299 & 380 & 588 & 908 \\
Sales & 161510.1 & 425501.7 & 27440.5 & 43630.18 & 72846.9 & 149369.8 & 267613.9 \\
VA & 34713.3 & 62704.8 & 4557.8 & 10117.5 & 18171.1 & 37616.9 & 66667.0 \\
\hline 2006: & $\mathbf{4 3 6}$ obs \\
\hline Empl & 570 & 939 & 184 & 268 & 363 & 592 & 917 \\
Sales & 170179.4 & 471125.7 & 18062.0 & 35823.8 & 72632.8 & 153729.8 & 277325.3 \\
VA & 32205.4 & 60729.2 & 7214.9 & 12022.1 & 18697.6 & 34321.4 & 60726.2 \\
\hline \hline
\end{tabular}

and profits. All of these variables are significantly positively related to each other, although the correlations between profit levels and levels of the other variables are smaller in magnitude. Value added is better correlated with each of the other variables. Hence, we can consider that it is a good indicator of size, and it is also also strongly related to financial performance.

Table 3 shows descriptive statistics for firm age and $C_{20}^{4}$ ratios in 2006 (where the $C_{20}^{4}$ ratio is calculated as the cumulative market share of the 4 largest firms divided by the cumulative market share of the 20 largest firms in a sector). In this case we have also classified firms according to whether they are young (less than 10 years), medium-aged (between 10 and 19 years) or old (20 years or more). Our results show that the majority of firms which are large have been operating in the market for 20 years or more. Furthermore, for old firms the average age is 39 years. Hence, the evidence for Spanish large manufacturing firms is that they are rather old. Table 3 also contains information on how $C_{20}^{4}$ ratios vary with respect to the age of the sector's largest firm. We have 159 sectors at four-digit level, where the mean $C_{20}^{4}$ ratio takes values between $0.53-0.58$. If we consider the $C_{20}^{4}$ ratio at the level of three-digit sectors, the concentration ratio diminishes. We also observe that sectors in which the largest firm is younger tend to be less concentrated.

Figure 1 shows the distribution of $C_{20}^{4}$ concentration ratios at 4 digit level 
Table 2: Correlation matrix of size levels in 2006 for Spanish manufacturing firms.

\begin{tabular}{l|cccc}
\hline \hline & Empl & Sales & VA & Profits \\
\hline $\begin{array}{l}\text { Empl } \\
p \text {-value } \\
\text { obs }\end{array}$ & 1 & & & \\
\hline Sales & 436 & & & \\
$p$-value & 0.8337 & 1 & & \\
obs & 436 & 447 & & \\
\hline VA & 0.9029 & 0.8519 & 1 & \\
$p$-value & 0.0000 & 0.0000 & & \\
obs & 436 & 447 & 452 & \\
\hline Profits & 0.3360 & 0.2336 & 0.5784 & 1 \\
$p$-value & 0.0000 & 0.0000 & 0.0000 & \\
obs & 436 & 447 & 452 & 452 \\
\hline \hline
\end{tabular}

Table 3: Firm age and $C_{20}^{4}$ ratios for Spanish manufacturing firms in 2006, for young firms (<10 years), medium firms (10-19 years) and old firms (20+ years). $C_{20}^{4}$ ratios are disaggregated by age according to the age of the largest firm in the sector.

\begin{tabular}{|c|c|c|c|c|}
\hline & \multicolumn{4}{|c|}{ Firm age } \\
\hline Young & 50 & 7.58 & 7.5 & 0.99 \\
\hline Medium-aged & 116 & 14.96 & 15 & 2.97 \\
\hline Old & 291 & 40.83 & 38 & 16.28 \\
\hline Total & 457 & 30.63 & 27 & 18.92 \\
\hline & \multicolumn{4}{|c|}{$C_{20}^{4}$ four-digits } \\
\hline Young & 20 & 0.53 & 0.55 & 0.21 \\
\hline Medium-aged & 30 & 0.60 & 0.61 & 0.21 \\
\hline Old & 73 & 0.60 & 0.59 & 0.22 \\
\hline Total & 123 & 0.59 & 0.59 & 0.21 \\
\hline & \multicolumn{4}{|c|}{$C_{20}^{4}$ three-digits } \\
\hline Young & 8 & 0.41 & 0.40 & 0.16 \\
\hline Medium-aged & 19 & 0.52 & 0.50 & 0.14 \\
\hline Old & 36 & 0.53 & 0.45 & 0.21 \\
\hline Total & 63 & 0.51 & 0.46 & 0.19 \\
\hline
\end{tabular}




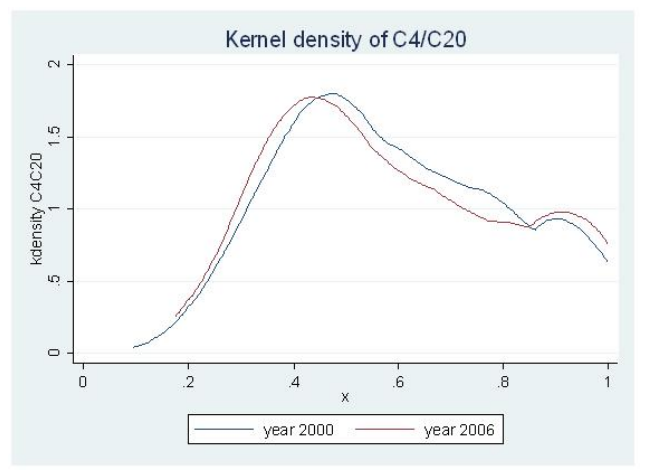

Figure 1: Distribution of the $C_{20}^{4}$ for four-digit sectors.

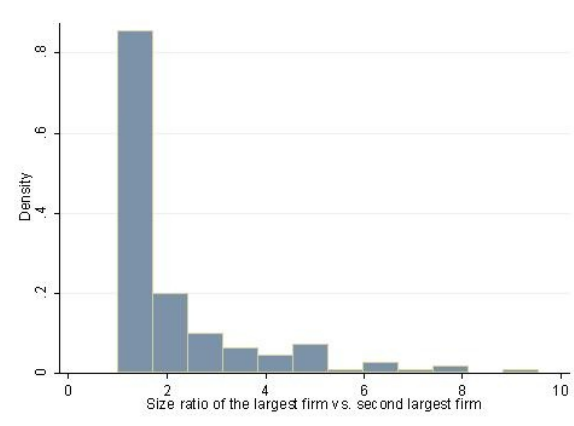

Figure 2: Size ratios of the largest firm vs second largest firm in 4-digit sectors, for the year 2006. Firm size measured in terms of number of employees. Size ratios are restricted to taking values of at least one, by construction.

sectors. Values of $C_{20}^{4}$ must lie within an upper bound at 1.00 and a lower bound of 0.20 , by construction. Therefore, as we can observe, the empirical distribution covers most of the available support, but with higher density on the value interval between 0.40 and 0.60 .

Figure 2 shows the distribution of the ratio of the size of the largest to the second largest firm classified at four-digit sectors. The lower limit at 1.00 corresponds to the case where the leader is almost the same size as the second largest firm. In most cases, the leader is not much more than twice as large as the second largest firm, although in some cases the leader can be ten times larger, or even more.

Growth rates are calculated by taking log-differences of size levels:

$$
G R_{i, t}=\log \left(X_{i, t}\right)-\log \left(X_{i, t-1}\right)
$$

where $X$ is a measure of firm size ( $X \in\{$ Sales, Employment, ValueAdded $\}$ ) for firm $i$ at time $t .^{10}$

\footnotetext{
${ }^{10}$ This way of calculating growth rates is the preferred choice according to Tornqvist et al. (1985).
} 

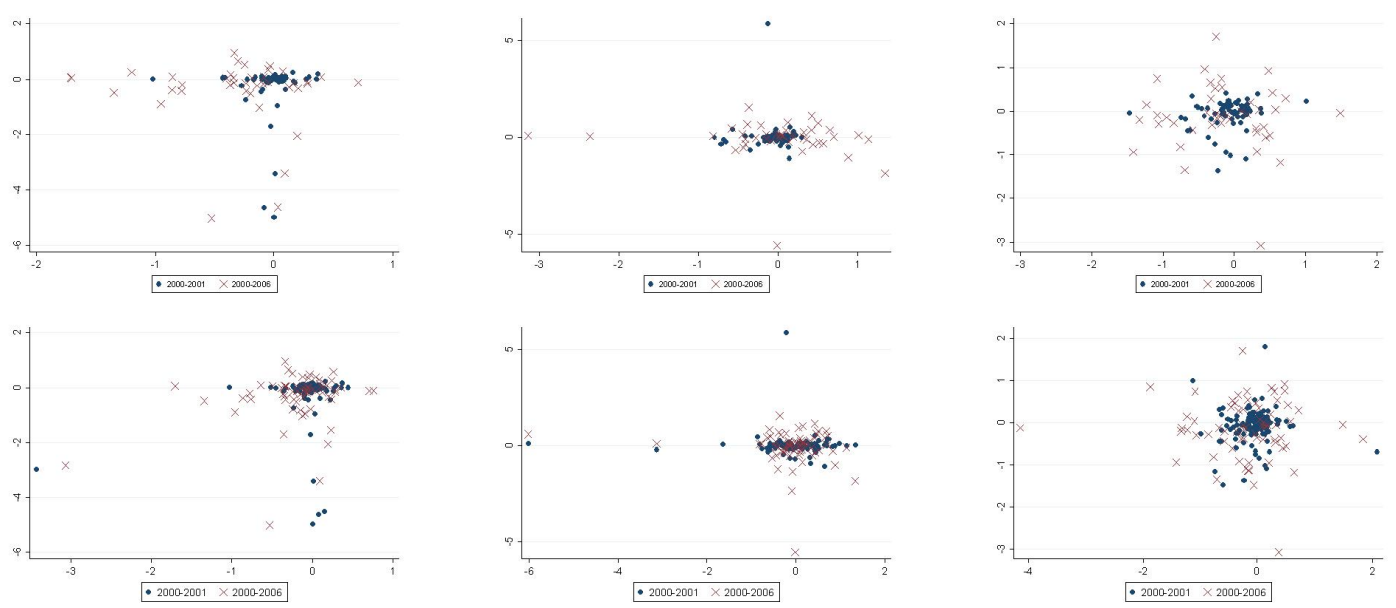

Figure 3: Scatterplots of the growth (2000-2001) of the largest vs second largest firm in each sector. Three-digit sectors are shown on the top row, and four-digit sectors are shown on the bottom row. Growth is measured in terms of employees (left), sales (centre) or value added (right).

\section{Leader-follower correlations}

\subsection{Scatterplots}

We begin our analysis with some correlations, following Sutton (2007). Figure 3 shows the correlations of the growth rates of the largest and second largest firms that are in the same sectors, where the sector is defined alternatively on a threedigit and four-digit level of aggregation. Growth is defined in terms of employment, sales or value added, and growth is measured over a one-year period or a 7-year period. The most striking finding is that the growth of one firm appears to be independent of the growth of its rival, in each case. Our investigations into interfirm competition do not appear to have made a good start and find results similar to Sutton (2007).

Data constraints prevent us from taking a finer level of disaggregation beyond the four-digit level. It should be mentioned, however, that even at the four-digit level, in a number of cases the largest firm in its four-digit industry is relatively small and would not qualify as a "large firm" according to any standard definition. 


\subsection{Correlated growth profiles}

We pursue our investigation of inter-firm competition by focusing on one industry at a time, and within this industry focusing on the correlation between the annual growth rates of the two largest firms. For each industry $j$ we calculate the correlation coefficient $\rho_{j}$ relating the growth of the largest firm (firm $A$ ) to the growth of the second largest (firm $B$ ), according to the following formula:

$$
\rho_{j}=\frac{\sum_{t=2000}^{2006}\left(G R_{A, t}-\overline{G R_{A}}\right)\left(G R_{B, t}-\overline{G R_{B}}\right)}{\sigma_{A} \sigma_{B}}
$$

Figures 4 and 5 show the distributions of the correlation coefficients, $\rho_{j}$, at the level of three-digit and four-digit sectors, respectively. (Sutton, 2007, p226) shows that negative correlation is more likely to be found in the market share dynamics of the two largest firms in the case of industries that are essentially duopolies. In our analysis, we observe both negative and positive correlations between the growth profiles of the two largest firms in the same industry. In contrast to what we would expect if growth of rival firms was merely random, the mode of the distribution of $\rho_{j}$ does not appear to be located around zero. This could signal that there might be some structure in the growth profiles of the largest vs second largest firms. In some cases, such as value-added growth at the three-digit level, the distribution of $\rho_{j}$ appears to be bimodal. ${ }^{11}$ Formal multimodality tests do not suggest that this bimodality is statistically significant at conventional levels, however (see the figure captions for the $p$-values).

\subsection{Discussion}

So far, our analysis seems to provide justification to theoretical and empirical models that assume that the growth rates of different firms can be modelled as

\footnotetext{
${ }^{11}$ Bimodality in the distribution of $\rho_{j}$ would suggest that there are two competitive regimes at work in our dataset. In some cases, firms in the same industry may share the same fate (positive correlation in growth rates). In other cases, there may be a negative correlation such that sales growth of one firm is associated with a decline of sales for the other firm. One could summarize this structure of interactions between firms by using catchphrases such as "love me or hate me, but nothing in between." Significant bimodality in the distribution of $\rho_{j}$ was found for French data in an earlier investigation in Coad and Valente (2010).
} 


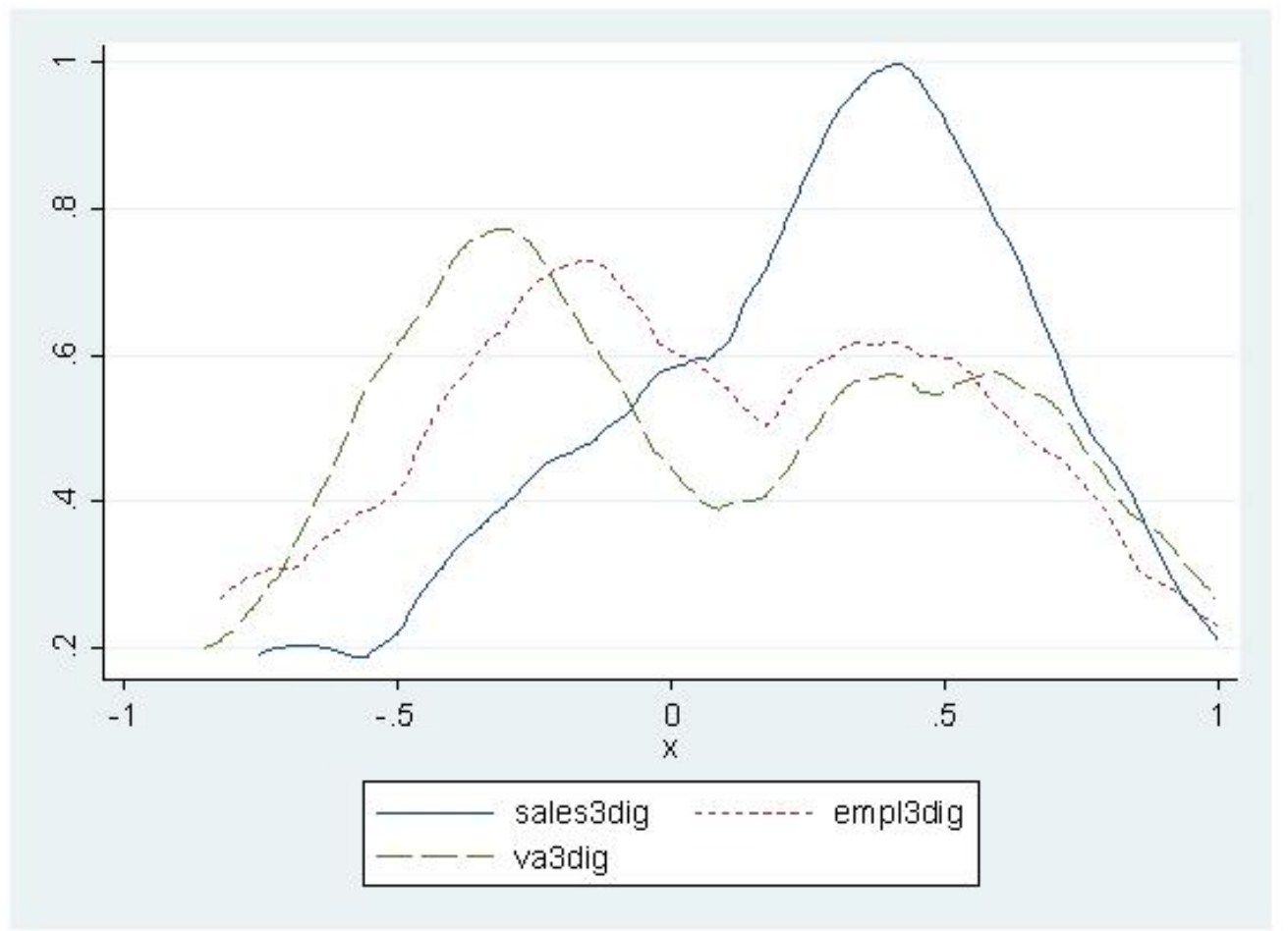

Figure 4: Kernel density showing the correlations between the annual growth rates of the leader and second largest firms in those 3-digit industries for which at least 5 datapoints exist (i.e. at least 5 annual growth rates for leader vs follower for the period 2000-2006) for the whole database. In other words, this figure shows the distribution of the $\rho_{j}$ coefficients obtained from equation (2). We restrict ourselves to industries in which the largest firm is not more than 10 times larger than the second largest firm in the year 2000. Annual growth rates are measured in terms of Sales (32 obs), Employment (32 obs) or Value Added (30 obs). Kernel bandwidth $=0.15$. Tests for multimodality, following Silverman (1981) and Hall and York (2001) (using gbutils 5.2) cannot convincingly reject the hypothesis that the distribution is unimodal - the $p$-values are 0.330 (Sales), 0.215 (Employment) and 0.051 (VA). 


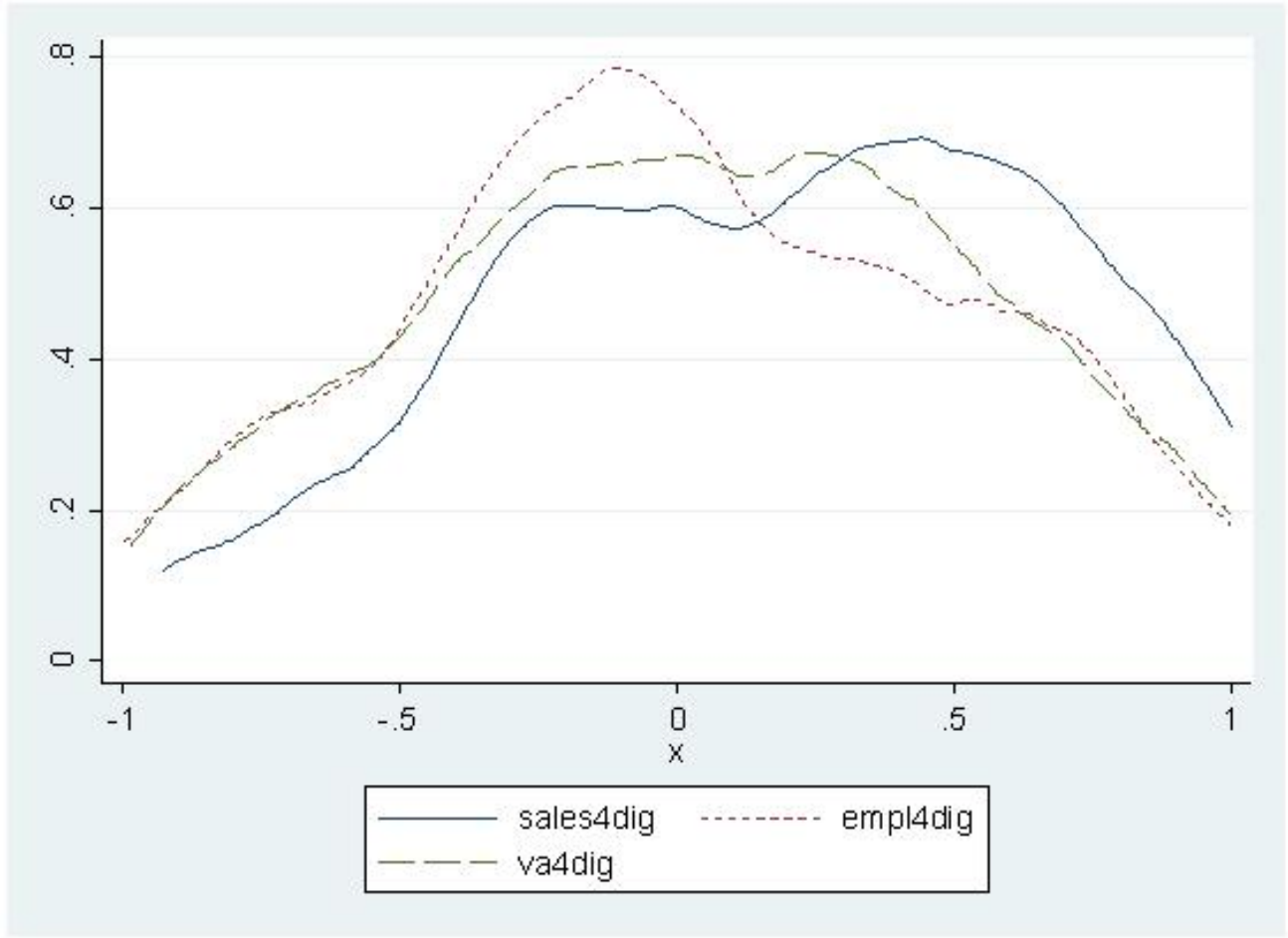

Figure 5: Kernel density showing the correlations between the annual growth rates of the leader and second largest firms in those 4-digit industries for which at least 5 datapoints exist (i.e. at least 5 annual growth rates for leader vs follower for the period 2000-2006) for the whole database. In other words, this figure shows the distribution of the $\rho_{j}$ coefficients obtained from equation (2). We restrict ourselves to industries in which the largest firm is not more than 10 times larger than the second largest firm in the year 2000. Annual growth rates are measured in terms of Sales ( 85 obs), Employment ( 83 obs) or Value Added (79 obs). Kernel bandwidth $=0.15$. Tests for multimodality, following Silverman (1981) and Hall and York (2001) (using gbutils 5.2) cannot convincingly reject the hypothesis that the distribution is unimodal - the $p$-values are 0.116 (Sales), 0.466 (Employment) and 0.124 (VA). 
being independent. For example, our results provide support to Gibrat's model of firm growth, which 'explains' growth in terms of stochastic multiplicative shocks, that are independent across firms. Even when analysing the growth of rival firms, the following statement still holds: "The most elementary 'fact' about corporate growth thrown up by econometric work on both large and small firms is that firm size follows a random walk" (Geroski, 2000, p. 169).

Our failure to find interdependencies in the growth rates of firms in the same industries may perhaps be explained by arguing that firms are multiproduct entities that are diversified into many submarkets (with competition taking place at the submarket level), and that sectoral classification schemes (such as the threedigit to four-digit levels analyzed here) are too broadly defined to be able to detect significant competitive interactions. Although it is well known that large firms often diversify into several lines of business, however it has nonetheless been shown that firms in the same industries often have similar diversification patterns (Teece et al., 1994), such that large firms with the same sector of principal activity are likely to have some degree of 'multi-market contact' with their rivals even if they are diversified into more than one market. It has also been observed that European firms are more focused than their US counterparts (Geroski and Gugler, 2004, p603).

It seems to us that if competition cannot be detected at the firm level, nor even at the level of rival firms in the same sectors, then competition is a concept that is only relevant at finely disaggregated levels of analysis, and that, as a consequence, we could take the extreme view that it is not relevant to mention competition effects in discussions of firm-level performance. In other words, our results seem to suggest that firms can be modeled "as if" they are independent from each other. Antitrust investigations take the 'relevant market', defined as narrowly as possible, as the starting point for investigations of inter-firm competition (Geroski and Griffith, 2004). However, these 'relevant markets' are extremely difficult to define, and the boundaries of these markets can change from year to year (Geroski and Griffith, 2004). While we consider that competitive interdependence is a useful concept at the level of antitrust 'relevant markets', it is far less useful at the firm 
level. ${ }^{12}$ Large firms can be seen as aggregated entities, being active in several different sectors, and being diversified into numerous lines of business. Perhaps there might be some kind of 'law of large numbers' at work, according to which the evidence of inter-firm rivalry tends to disappear with aggregation. While direct competition may sometimes have visible effects at the level of finely-disaggregated markets, statistical aggregation effects may wash away evidence of competition as one takes a more aggregated level of analysis.

Although our correlation analysis did not yield evidence of inter-firm competition, we pursue our analysis in the context of multivariate regressions, controlling for other influences and also accounting for the endogeneity of the growth rates of interdependent firms.

\section{Multivariate regressions}

\subsection{Standard regressions}

Equation 3 shows the regression equation.

$$
g_{i, t}=c+\beta \operatorname{Riv} G r_{i, t}+\gamma C T R L_{i, t}+\varepsilon_{i, t}
$$

where $\operatorname{Riv} G r_{i, t}$ corresponds to the growth of rivals, and is defined as $R i v G r_{i, t}=$ $\frac{\sum_{j \neq i}^{m_{r}} g_{j, t}}{m_{r}-1}$ where $m_{r}$ corresponds to the number $m$ of firms in sector $r$. CTR $R L_{i, t}$ corresponds to a set of control variables, i.e. lagged size, lagged growth, age, 3digit industry growth and also sector and year dummies. ${ }^{13}$

\footnotetext{
${ }^{12}$ There is (by definition) nothing that we can do to resolve the tautology that competition only exists once 'relevant markets' have been properly delineated, and that relevant markets are by definition composed of competing firms. Therefore a sceptic might point out that we fail to find evidence of competitive interdependence because we have failed to properly delineate the relevant markets. However, we would reply that competitive interdependence does not appear to be a relevant concept at the firm-level.

${ }^{13}$ Note that we include a lagged dependent variable, which could be a source of Nickell-bias in a model with time-invariant fixed effects and strong autocorrelation. In our particular case, however, the evidence suggests that fixed effects are not a major concern for firm growth rates, because there is more variation in the time series of a single firm's growth rates, than there is across different firms. In other words, the within component of growth rate variance is larger than the between component (Geroski and Gugler, 2004). Furthermore, autocorrelation of growth
} 
Regression results of OLS, LAD and WLS are presented in Table 4. Following Geroski and Gugler (2004), our OLS estimations show that rival growth appears to have a significant positive impact on firm growth, regardless of whether we consider competition at the level of three- or four-digit sectors. Our estimates for the impact of rival growth are not significant, however, when analogous regressions are performed using Least Absolute Deviation (LAD) regressions (also known as 'median regressions,' which are better suited to the case of non-Gaussian growth rate distributions). Weighted Least Squares (WLS) regressions (where firms are weighted by lagged size in order to account for the different importance of firms of different sizes) also yield positive and significant estimates for the coefficient of rival growth on firm growth.

Concerning the other coefficients, our results are in line with the previous literature. On the one hand, firm size shows a significant negative impact on firm growth. This is an interesting feature given that our results would reject Gibrat's Law even for large firms (for a survey of the Gibrat's Law literature, see (Coad, 2009, Chapter 4)). In line with previous findings, firm age has a negative impact on firm growth, although this effect is not always significant.

Finally, we should also mention the relatively high explanatory power of the regressions, especially for the OLS regressions at four-digit sectors.

A drawback of the estimates reported in Table 4, however, is that problems of endogenous growth of rival firms make the resulting coefficient estimates unreliable. Despite this endogeneity, we consider it worthwhile to present these initial results for two reasons. First, our results can now be compared to previous work. Second, our results can shed light on the associations between the variables without addressing issues of causality. Nevertheless, in the next section we will take issues of endogenous regressors into account.

rates is often rather small in magnitude, and indeed we observe it to be small in our dataset. We conclude that Nickell-bias can be expected to be especially small in the present context. 
Table 4: Regression results from estimation of equation (3) for Spanish manufacturing firms with 250 workers or more. LAD regression results are taken after 50 bootstrap replications.

\begin{tabular}{|c|c|c|c|c|c|c|c|c|c|}
\hline & \multicolumn{3}{|c|}{$\overline{\text { OLS }}$} & \multicolumn{3}{|c|}{$\overline{\text { LAD }}$} & \multicolumn{3}{|c|}{ WLS } \\
\hline & Labour & Sales & VA & Labour & Sales & VA & Labour & Sales & VA \\
\hline \multicolumn{10}{|l|}{ 4-digit rivalry } \\
\hline $\operatorname{RivGr}(\mathrm{t})$ & 2.0690 & 3.5792 & 2.4987 & 0.1533 & 1.1219 & 0.3425 & 1.8481 & 3.5699 & 2.3659 \\
\hline$t$-stat & 3.26 & 5.93 & 4.49 & 0.68 & 2.39 & 1.34 & 2.96 & 5.77 & 4.31 \\
\hline Size & -0.1513 & -0.0707 & -0.1261 & -0.0132 & -0.0015 & -0.0205 & -0.0647 & -0.0485 & -0.1007 \\
\hline$t$-stat & -4.62 & -3.88 & -5.28 & 2.91 & -0.39 & -3.59 & -3.63 & -3.42 & -5.97 \\
\hline Age & -0.0123 & -0.01428 & -0.0146 & -0.0031 & -0.0048 & -0.0031 & -0.0108 & -0.0095 & -0.0099 \\
\hline$t$-stat & -1.37 & -1.23 & -1.19 & -1.19 & 1.21 & -0.55 & -1.39 & -0.94 & -0.89 \\
\hline$g_{i, t-1}$ & -0.3023 & -0.2363 & -0.2136 & -0.0006 & -0.0106 & -0.0752 & -0.1927 & -0.1298 & -0.1382 \\
\hline$t$-stat & -4.43 & -3.32 & -3.96 & -0.04 & -0.65 & -1.74 & -2.58 & -2.20 & -3.35 \\
\hline Constant & yes & yes & yes & yes & yes & yes & yes & yes & yes \\
\hline Sector growth & yes & yes & yes & yes & yes & yes & yes & yes & yes \\
\hline Sector dummies & yes & yes & yes & yes & yes & yes & yes & yes & yes \\
\hline Year dummies & yes & yes & yes & yes & yes & yes & yes & yes & yes \\
\hline$R^{2}$ & 0.3286 & 0.3273 & 0.2741 & 0.0423 & 0.0512 & 0.0431 & 0.2196 & 0.2609 & 0.2107 \\
\hline Obs. & 3125 & 3214 & 3179 & 3125 & 3214 & 3179 & 3124 & 3214 & 3179 \\
\hline \multicolumn{10}{|l|}{ 3-digit rivalry } \\
\hline $\operatorname{RivGr}(\mathrm{t})$ & 0.0802 & -0.0727 & 0.1085 & 0.0068 & 0.0013 & 0.0028 & 0.0731 & -0.0662 & 0.1052 \\
\hline$t$-stat & 0.65 & -0.55 & 0.69 & 0.66 & 0.02 & 0.09 & 0.65 & -0.45 & 0.73 \\
\hline Size & -0.1556 & -0.0859 & -0.1287 & -0.0149 & -0.0041 & -0.0243 & -0.0654 & -0.0622 & -0.1022 \\
\hline$t$-stat & -4.74 & -5.21 & -5.82 & -4.26 & -1.18 & -4.27 & -3.71 & -4.64 & -6.44 \\
\hline Age & -0.0104 & -0.0138 & -0.0098 & -0.0036 & -0.0047 & -0.0009 & -0.0080 & -0.0108 & -0.0051 \\
\hline$t$-stat & -1.15 & -1.19 & -0.79 & -1.54 & -1.42 & -0.19 & -1.09 & -1.07 & -0.47 \\
\hline$g_{i, t-1}$ & -0.3561 & -0.3303 & -0.2534 & -0.0067 & -0.0074 & -0.0652 & -0.2203 & -0.1894 & -0.1563 \\
\hline$t$-stat & -4.97 & -4.25 & -4.19 & -0.44 & -0.52 & -1.65 & -2.85 & -2.84 & -3.44 \\
\hline Constant & yes & yes & yes & yes & yes & yes & yes & yes & yes \\
\hline Sector growth & yes & yes & yes & yes & yes & yes & yes & yes & yes \\
\hline Sector dummies & yes & yes & yes & yes & yes & yes & yes & yes & yes \\
\hline Year dummies & yes & yes & yes & yes & yes & yes & yes & yes & yes \\
\hline$R^{2}$ & 0.2429 & 0.1789 & 0.1823 & 0.0311 & 0.0333 & 0.0321 & 0.1268 & 0.1016 & 0.1217 \\
\hline Obs. & 3125 & 3214 & 3179 & 3124 & 3214 & 3179 & 3124 & 3214 & 3179 \\
\hline
\end{tabular}




\section{$5.2 \quad$ Peer-effects econometrics}

In this section we apply a peer-effects estimator to analyze firm growth rates, in the hope of finding evidence of inter-firm competition. While peer-effects econometrics has been applied many times to analysis of neighborhood effects, substance use among teenagers, and peer group effects among university room-mates (see Soetevent (2006) for a survey), it has recently been applied in the context of firm growth. Oberhofer and Pfaffermayr (2010) investigate the growth of multinational groups, and observe positive externalities within vertically organized multinational networks, although horizontally organized networks display negative growth spillovers.

We follow the methodology used in Oberhofer and Pfaffermayr (2010) and use the instrumental-variable estimator proposed by Lee (2007) (see also Bramoullé et al. (2009)). As stressed by Davezies et al. (2009), Lee (2007)'s identification strategy crucially requires knowledge of peer group sizes, with at least three groups having a different size. With this in mind, we define a firm's 'peer group' in terms of the other firms (having 250 or more employees in the initial time period) in the same three-digit or four-digit sector. In our regressions, identification of the growth spillover effects depends crucially on variation in group size.

Consider the following regression equation:

$$
g_{i r}=\lambda \cdot\left(\frac{\sum_{j \neq i}^{m_{r}} g_{j r}}{m_{r}-1}\right)+\gamma X_{i r}+\mu_{r}+\epsilon_{i r}
$$

where $X_{i r}$ corresponds to a set of exogenous control variables. In this case, the parameter of interest is $\lambda$, which indicates how a firm's growth is influenced by the growth of its rivals. $m_{r}$ corresponds to the number $m$ of firms in sector $r$. $\mu_{r}$ is a group-specific fixed effect.

The econometric issue is that the growth of rival firms may simultaneously affect each other. This problem has been called the 'reflection problem' by Manski (1993), because "the problem is similar to that of interpreting the almost simultaneous movements of a person and his reflection in a mirror" (Manski, 1993, p. 532). 
Equation (4) can be rewritten as:

$$
g_{i r}=\frac{\lambda}{m_{r}-1}\left(m_{r} \bar{g}_{r}-g_{i r}\right)+\gamma X_{i r}+\mu_{r}+\epsilon_{i r}
$$

Taking averages across groups, we obtain the between-group equation:

$$
\overline{g_{r}}=\frac{\lambda}{m_{r}-1}\left(m_{r} \bar{g}_{r}-\bar{g}_{r}\right)+\gamma \bar{X}_{r}+\mu_{r}+\bar{\epsilon}_{r}
$$

which can be rearranged to yield:

$$
\overline{g_{r}}=\frac{1}{1-\lambda}\left(\gamma \bar{X}_{r}+\mu_{r}+\bar{\epsilon}_{r}\right)
$$

Subtracting (7) from (5) we obtain:

$$
\left(g_{i r}-\bar{g}_{r}\right)=-\lambda \frac{\left(g_{i r}-\bar{g}_{r}\right)}{\left(m_{r}-1\right)}+\gamma\left(X_{i r}-\bar{X}_{r}\right)+\left(\epsilon_{i r}-\overline{\epsilon_{r}}\right)
$$

Equation (8) corresponds to the within-group equation, in which an individual firm's growth is related to the average growth of the rival firms in the same sector. The first term on the right-hand side is clearly endogenous - $g_{i t}$ has an influence on $g_{j t}$, but $g_{j t}$ also influences $g_{i t}$. To deal with this endogeneity, we apply instrumentalvariable (IV) techniques (following Oberhofer and Pfaffermayr (2010).) First, we use the exogenous variables multiplied by $\frac{1}{\left(m_{r}-1\right)}$ as instruments in a two-stage least squares (2SLS) regression of equation (8) to obtain a consistent initial estimator of $\lambda$. Our IV diagnostics for the first-stage regressions pertain to this regression. Second, we use this estimate of $\lambda$ to derive an improved instrument, that we use in another 2SLS estimation of equation (8). ${ }^{14}$

Table 5 contains the estimation results using the labour, sales and value added growth rates as dependent variables. Our results are also differentiated according with three different firm sizes: 100, 200 and 250 workers or more. The estimated impact of rival growth on firm growth is always negative, and statistically significant in most cases. In the case of employment growth, the coefficient of rival growth is only significant for the subsample that includes all firms with 100 or

\footnotetext{
${ }^{14}$ See Lee (2007, p. 345$)$.
} 
more employees. For value added growth, however, negative and significant effects of rival growth can be found in all samples.

The results concerning the firm size and firm age are in line with the estimations obtained in Table 4. On the one hand, firm size has a negative impact on firm growth, regardless the variable. Hence, our results controlling for endogenous peer-group effects would still reject Gibrat's Law. With respect to firm age, our results show that there is a stable negative impact on firm growth. In general, this coefficient is significant. However, for firms with 250 workers or more the coefficient is only significant in the sales growth equation.

Lagged firm growth also shows a significant and negative impact on current firm growth. We observe that firms with 250 or more workers are more affected by the negative impact of previous employment growth, firms with 200 or more workers show a stronger negative autocorrelation for sales growth and firms with 100 or more workers present a larger coefficient the past value added growth. Hence, there is some tentative evidence that growth rate autocorrelation has different effects on the growth of firms of different sizes. ${ }^{15}$

Finally, we also check for differences over time. Table 6 shows the evolution across years of the impact of rival growth for our three variables, and for different firm size subsamples. In the majority of cases, our estimates of the coefficient of rival growth tend to be negative and significant. Furthermore, we may observe that firms with 100 or more workers display a higher negative impact of rivalry than their counterparts.

\section{Conclusion}

Theoretical work into inter-firm competition has taken many different views on the nature of rivalry, ranging from predictions of zero-sum games, to tacit collusion in settings of multimarket contact, and even to cooperation between competitors.

\footnotetext{
${ }^{15}$ However, we do not wish to unduly emphasize the magnitudes of the autocorrelation coefficients here, since it has been shown that least-squares estimation of firm growth rate autocorrelation coefficient magnitudes is strongly affected by the non-Gaussian nature of firm growth rate distributions (Bottazzi et al., 2010, Table 3).
} 
Table 5: Pooled regression results from Peer-effects estimations for Spanish manufacturing firms according with firm size: IV estimation of equation (8). IV diagnostics include the first-stage $R^{2}$, the Angrist-Pischke multivariate F-test of excluded instruments, the Anderson canonical correlation LM statistic (whether the equation is identified, i.e. whether the excluded instruments are relevant), and the Anderson-Rubin Wald test (significance of the endogenous regressors).

\begin{tabular}{|c|c|c|c|c|c|c|c|c|c|}
\hline & \multicolumn{3}{|c|}{$\geq 100$ employees } & \multicolumn{3}{|c|}{$\geq 200$ employees } & \multicolumn{3}{|c|}{$\geq 250$ employees } \\
\hline & Empl & Sales & $\overline{\text { VA }}$ & Empl & Sales & $\overline{\text { VA }}$ & Empl & Sales & $\mathbf{V A}$ \\
\hline \multicolumn{10}{|c|}{ Rival group at 4-digit sectoral level } \\
\hline RivGr & -0.361 & -0.282 & -0.295 & -0.229 & -0.267 & -0.537 & -0.336 & -0.194 & -0.553 \\
\hline s.e. & 0.134 & 0.239 & 0.188 & 0.124 & 0.269 & 0.107 & 0.086 & 0.255 & 0.082 \\
\hline$p$-value & 0.007 & 0.239 & 0.117 & 0.065 & 0.321 & 0.000 & 0.000 & 0.447 & 0.000 \\
\hline Empl & -0.070 & -0.023 & -0.064 & -0.073 & -0.021 & -0.053 & -0.045 & -0.023 & -0.038 \\
\hline s.e. & 0.005 & 0.004 & 0.005 & 0.008 & 0.006 & 0.007 & 0.009 & 0.008 & 0.008 \\
\hline$p$-value & 0.000 & 0.000 & 0.000 & 0.000 & 0.000 & 0.000 & 0.000 & 0.005 & 0.000 \\
\hline Age & -0.013 & -0.021 & -0.020 & -0.018 & -0.017 & -0.018 & -0.010 & -0.016 & -0.013 \\
\hline s.e. & 0.004 & 0.005 & 0.005 & 0.006 & 0.007 & 0.007 & 0.006 & 0.008 & 0.008 \\
\hline$p$-value & 0.001 & 0.000 & 0.000 & 0.003 & 0.014 & 0.006 & 0.108 & 0.052 & 0.086 \\
\hline$g_{i, t-1}$ & -0.259 & -0.258 & -0.215 & -0.234 & -0.182 & -0.139 & -0.248 & -0.174 & -0.147 \\
\hline s.e. & 0.010 & 0.014 & 0.011 & 0.017 & 0.024 & 0.014 & 0.021 & 0.034 & 0.016 \\
\hline$p$-value & 0.000 & 0.000 & 0.000 & 0.000 & 0.000 & 0.000 & 0.000 & 0.000 & 0.000 \\
\hline Obs & 11533 & 11969 & 11776 & 4400 & 4538 & 4483 & 2977 & 3067 & 3029 \\
\hline$R^{2}$ 1st stage & 0.1583 & 0.1086 & 0.1102 & 0.1334 & 0.0803 & 0.1671 & 0.1800 & 0.1049 & 0.1772 \\
\hline Angrist-Pischke & 443.29 & 226.12 & 262.84 & 121.89 & 56.79 & 178.09 & 125.08 & 49.71 & 136.65 \\
\hline$p$-value & 0.0000 & 0.0000 & 0.0000 & 0.0000 & 0.0000 & 0.0000 & 0.0000 & 0.0000 & 0.0000 \\
\hline Anderson LM & 1192.93 & 642.29 & 739.39 & 338.04 & 164.40 & 477.94 & 333.84 & 142.49 & 361.71 \\
\hline$p$-value & 0.0000 & 0.0000 & 0.0000 & 0.0000 & 0.0000 & 0.0000 & 0.0000 & 0.0000 & 0.0000 \\
\hline Anderson-Rubin & 7.43 & 3.80 & 8.48 & 8.52 & 5.86 & 29.77 & 7.31 & 12.89 & 21.36 \\
\hline$p$-value & 0.0001 & 0.0098 & 0.0000 & 0.0000 & 0.0005 & 0.0000 & 0.0001 & 0.0000 & 0.0000 \\
\hline \multicolumn{10}{|c|}{ Rival group at 3-digit sectoral level } \\
\hline RivGr & -1.356 & -10.994 & -1.016 & -0.110 & -0.213 & -0.392 & -0.123 & -2.393 & -0.330 \\
\hline s.e. & 0.341 & 5.469 & 0.545 & 0.124 & 0.295 & 0.145 & 0.129 & 0.288 & 0.164 \\
\hline$p$-value & 0.000 & 0.044 & 0.063 & 0.374 & 0.471 & 0.007 & 0.340 & 0.000 & 0.044 \\
\hline Empl & -0.068 & -0.008 & -0.064 & -0.091 & -0.029 & -0.062 & -0.073 & -0.009 & -0.053 \\
\hline s.e. & 0.005 & 0.009 & 0.005 & 0.008 & 0.006 & 0.007 & 0.010 & 0.006 & 0.008 \\
\hline$p$-value & 0.000 & 0.359 & 0.000 & 0.000 & 0.000 & 0.000 & 0.000 & 0.111 & 0.000 \\
\hline Age & -0.014 & -0.004 & -0.020 & -0.017 & -0.015 & -0.018 & -0.010 & -0.010 & -0.013 \\
\hline s.e. & 0.004 & 0.009 & 0.005 & 0.007 & 0.007 & 0.007 & 0.007 & 0.006 & 0.008 \\
\hline$p$-value & 0.000 & 0.627 & 0.000 & 0.007 & 0.043 & 0.013 & 0.171 & 0.081 & 0.120 \\
\hline$g_{i, t-1}$ & -0.253 & -0.030 & -0.211 & -0.284 & -0.231 & -0.190 & -0.309 & -0.063 & -0.199 \\
\hline s.e. & 0.011 & 0.123 & 0.013 & 0.015 & 0.020 & 0.014 & 0.019 & 0.022 & 0.018 \\
\hline$p$-value & 0.000 & 0.808 & 0.000 & 0.000 & 0.000 & 0.000 & 0.000 & 0.004 & 0.000 \\
\hline Obs & 11788 & 12229 & 12040 & 4712 & 4862 & 4799 & 3287 & 3381 & 3337 \\
\hline$R^{2}$ 1st stage & 0.1404 & 0.0939 & 0.1177 & 0.1918 & 0.1153 & 0.2150 & 0.1878 & 0.0815 & 0.1853 \\
\hline Angrist-Pischke & 929.88 & 395.92 & 281.43 & 272.78 & 113.26 & 313.00 & 168.12 & 30.44 & 161.99 \\
\hline$p$-value & 0.0000 & 0.0000 & 0.0000 & 0.0000 & 0.0000 & 0.0000 & 0.0000 & 0.0000 & 0.0000 \\
\hline Anderson LM & 861.89 & 383.51 & 789.34 & 698.01 & 317.95 & 786.17 & 437.97 & 89.08 & 424.86 \\
\hline$p$-value & 0.0000 & 0.0000 & 0.0000 & 0.0000 & 0.0000 & 0.0000 & 0.0000 & 0.0000 & 0.0000 \\
\hline Anderson-Rubin & 8.56 & 4.7 & 8.84 & 2.97 & 6.29 & 25.86 & 3.35 & 7.73 & 16.54 \\
\hline$p$-value & 0.0000 & 0.0028 & 0.0000 & 0.0308 & 0.0003 & 0.0000 & 0.0182 & 0.0000 & 0.0000 \\
\hline
\end{tabular}


Table 6: Regression results from Peer-effects estimations for Spanish manufacturing firms according with firm size: IV estimation of the coefficient $\lambda$ in equation (8). Control variables are lagged size, age, lagged growth, sector growth, and sector and year dummies are included in the regressions but not reported here.

\begin{tabular}{|c|c|c|c|c|c|c|c|c|}
\hline \multicolumn{9}{|l|}{ Employees } \\
\hline & & 2000 & 2001 & 2002 & 2003 & 2004 & 2005 & 2006 \\
\hline \multirow[t]{3}{*}{$\geq 100 \mathrm{Empl}$} & RivGr & -1.055 & -0.880 & 0.387 & -4.760 & -13.474 & $\begin{array}{l}-3.572 \\
\end{array}$ & -0.042 \\
\hline & s.e. & 0.453 & 0.383 & 3.779 & 0.539 & 17.313 & 0.886 & 1.299 \\
\hline & Obs & 1656 & 1803 & 1858 & 1793 & 1710 & 1542 & 1426 \\
\hline \multirow[t]{3}{*}{$\geq 200 \mathrm{Empl}$} & RivGr & -0.342 & 0.485 & -1.216 & -0.477 & -1.022 & -1.072 & -3.262 \\
\hline & s.e. & 0.135 & 0.268 & 2.514 & 0.242 & 0.162 & 0.048 & 1.278 \\
\hline & Obs & 668 & 720 & 743 & 712 & 676 & 616 & 577 \\
\hline \multirow[t]{3}{*}{$\geq 250 \mathrm{Empl}$} & RivGr & -0.372 & 1.112 & -0.222 & 10.688 & -0.5460 & -1.048 & 15.988 \\
\hline & s.e. & 0.150 & 0.405 & 3.525 & 20.801 & 0.267 & 0.048 & 90.802 \\
\hline & Obs & 474 & 502 & 515 & 492 & 470 & 428 & 406 \\
\hline \multicolumn{9}{|l|}{ Sales } \\
\hline \multirow[t]{3}{*}{$\geq 100 \mathrm{Empl}$} & RivGr & 1.604 & -3.964 & -33.741 & -8.533 & -5.411 & -2.242 & 1.955 \\
\hline & s.e. & 9.208 & 1.237 & 99.773 & 2.140 & 5.928 & 0.281 & 8.726 \\
\hline & Obs & 1879 & 1881 & 1885 & 1820 & 1741 & 1565 & 1458 \\
\hline \multirow[t]{3}{*}{$\geq 200 \mathrm{Empl}$} & RivGr & -0.862 & -8.766 & -0.927 & -1.229 & -1.011 & -0.619 & -1.220 \\
\hline & s.e. & 0.195 & 1.709 & 2.124 & 0.177 & 0.250 & 0.130 & 0.518 \\
\hline & Obs & 745 & 746 & 751 & 720 & 685 & 625 & 590 \\
\hline \multirow[t]{3}{*}{$\geq 250 \mathrm{Empl}$} & RivGr & -0.859 & -6.908 & -6.703 & -1.072 & -0.848 & -0.6750 & -4.910 \\
\hline & s.e. & 0.193 & 1.309 & 1.466 & 0.287 & 0.762 & 0.102 & 5.76 \\
\hline & Obs & 517 & 520 & 521 & 497 & 476 & 434 & 416 \\
\hline \multicolumn{9}{|l|}{ VA } \\
\hline \multirow[t]{3}{*}{$\geq 100 \mathrm{Empl}$} & RivGr & -1.295 & -2.906 & 45.222 & -6.570 & $\begin{array}{l}-2.223 \\
\end{array}$ & -1.412 & 7.996 \\
\hline & s.e. & 1.030 & 1.731 & 241.753 & 1.428 & 0.784 & 0.852 & 17.203 \\
\hline & Obs & 1864 & 1865 & 1860 & 1786 & 1702 & 1535 & 1428 \\
\hline \multirow[t]{3}{*}{$\geq 200 \mathrm{Empl}$} & RivGr & -0.793 & 3.568 & -1.422 & -1.207 & -0.901 & -0.810 & 1.691 \\
\hline & s.e. & 0.139 & 8.229 & 2.016 & 0.169 & 0.139 & 0.087 & 0.733 \\
\hline & Obs & 740 & 742 & 743 & 706 & 673 & 615 & 580 \\
\hline \multirow[t]{3}{*}{$\geq 250 \mathrm{Empl}$} & RivGr & -0.749 & 4.522 & -3.329 & -1.296 & -0.569 & -0.837 & 1.951 \\
\hline & s.e. & 0.160 & 10.834 & 6.015 & 0.182 & 0.525 & 0.092 & 0.792 \\
\hline & Obs & 514 & 516 & 515 & 488 & 468 & 428 & 408 \\
\hline
\end{tabular}


Empirical work into the matter has not always found any evidence of inter-firm competition on firm growth, however. We measure growth in terms of employment, sales, and value added in our analysis of Spanish firms during the period 2000-2006. To begin with, we focus on correlations between the growth rates of the largest and second largest firms within the same industry, and are not able to reject the hypothesis that the growth of these rival firms shows no interdependence.

Standard multivariate regressions show that, if anything, the growth of rival firms is positively associated with each other. However, standard regressions are plagued by endogeneity problems - the growth of firm $i$ depends on the growth of firm $j$, which simultaneously depends on the growth of firm $i$. Applying a peereffects estimator to deal with this endogeneity allows us to find significant negative effects of rivals growth on the a firm's growth. Unless we control for issues of endogeneity due to rival firms' growth affecting each other simultaneously, using our peer-effects estimator, we are unable to detect the expected negative effects of rival's growth on firm growth. This seems to suggest that the negative effects of competition, at the firm-level, are not strong enough to counteract the bias introduced by endogeneity.

Our analysis looks for evidence of competition by applying two different approaches, and the results are not particularly easy to reconcile. At first, focusing on firm-dyad pairs, we are not able to reject the hypothesis that the growth of the largest firm in a sector is independent of the growth of the second largest. Afterwards, however, our peer-effects regression analysis focuses on a larger number of relatively large firms, and in this case we are able to detect the expected negative impact of rival growth on firm growth. Hence, when comparing results in the literature we should have in mind the econometric methodology applied and also the size and number of firms analyzed, and the degree of sectoral aggregation.

Future empirical work on inter-firm interdependence might fruitfully explore the significance of network effects (e.g. innovation networks) on firm performance using peer-effects estimators. 


\section{References}

Almeida, P. and Kogut, B. (1999). Localization of knowledge and the mobility of engineers in regional networks. Management Science, 45(7):905-917.

Audretsch, D. B., Prince, Y. M., and Thurik, A. R. (1999). Do small firms compete with large firms? Atlantic Economic Journal, 27(2):201-209.

Basker, E. (2007). The causes and consequences of Wal-Mart's growth. Journal of Economic Perspectives, 21(3):177-198.

Baum, J. and Korn, H. (1996). Competitive dynamics of interfirm rivalry. Academy of Management Journal, pages 255-291.

Bengtsson, M. and Kock, S. (2000). "Coopetition" in Business Networks - to Cooperate and Compete Simultaneously. Industrial Marketing Management, 29(5):411-426.

Bergman, M. and Rudholm, N. (2003). The relative importance of actual and potential competition: empirical evidence from the pharmaceuticals market. Journal of Industrial Economics, LI(4):455-467.

Boone, J., van Ours, J. C., and van der Weil, H. (2007). How (not) to measure competition. CEPR discussion paper 6275 .

Bottazzi, G., Coad, A., Jacoby, N., and Secchi, A. (2010). Corporate growth and industrial dynamics: Evidence from French manufacturing. Applied Economics, Forthcoming:DOI: 10.1080/00036840802400454.

Bottazzi, G. and Secchi, A. (2006). Explaining the distribution of firms growth rates. Rand Journal of Economics, 37:234-263.

Bramoullé, Y., Djebbari, H., and Fortin, B. (2009). Identification of peer effects through social networks. Journal of Econometrics, 150(1):41-55.

Coad, A. (2009). The Growth of Firms: A Survey of Theories and Empirical Evidence. Edward Elgar: Cheltenham, UK. 
Coad, A. and Valente, M. (2010). Hunting for a bogeyman? in search of statistical evidence of direct competition between firms. Max Planck Institute of Economics, mimeo.

Crane, A. (2005). In the company of spies: When competitive intelligence gathering becomes industrial espionage. Business Horizons, 48(3):233-240.

D'Aveni, R. (1994). Hypercompetition: Managing the Dynamics of Strategic Maneuvering. Free Press: New York.

Davezies, L., D'Haultfoeuille, X., and Fougère, D. (2009). Identification of peer effects using group size variation. Econometrics Journal, 12(3):397-413.

Dixit, A. (1980). The role of investment in entry-deterrence. Economic Journal, 90(357):95-106.

Evans, W. and Kessides, I. (1994). Living by the "Golden Rule": Multimarket contact in the US airline industry. Quarterly Journal of Economics, 109(2):341366.

Franco, A. M. and Filson, D. (2006). Spin-outs: knowledge diffusion through employee mobility. Rand Journal of Economics, 37(4):841-860.

Geroski, P. A. (1995). What do we know about entry? International Journal of Industrial Organization, 13:421-440.

Geroski, P. A. (2000). The growth of firms in theory and practice. In Foss, N. and Mahnke, V., editors, Competence, Governance, and Entrepreneurship. Oxford University Press, Oxford, UK.

Geroski, P. A. and Griffith, R. (2004). Identifying antitrust markets. In Neumann, M. and Weigand, J., editors, The International Handbook of Competition, chapter 8, pages 290-305. Edward Elgar: Cheltenham.

Geroski, P. A. and Gugler, K. (2004). Corporate growth convergence in Europe. Oxford Economic Papers, 56:597-620. 
Goolsbee, A. and Syverson, C. (2008). How do Incumbents Respond to the Threat of Entry? Evidence from the Major Airlines. Quarterly Journal of Economics, 123(4):1611-1633.

Hall, P. and York, M. (2001). On the calibration of Silverman's test for multimodality. Statistica Sinica, 11(2):515-536.

Hamel, G., Doz, Y., and Prahalad, C. (1989). Collaborate with your competitors and win. Harvard Business Review, 67(1):133-139.

Haskel, J. E., Pereira, S. C., and Slaughter, M. J. (2007). Does inward foreign direct investment boost the productivity of domestic firms? Review of Economics and Statistics, 89(3):482-496.

Hay, M. and Kamshad, K. (1994). Small firm growth: Intentions, implementation and impediments. Business Strategy Review, 5(3):49-68.

Ijiri, Y. and Simon, H. A. (1977). Skew Distributions and the Sizes of Business Firms. North Holland, Amsterdam.

Kato, M. and Honjo, Y. (2009). The persistence of market leadership: evidence from Japan. Industrial and Corporate Change, 18(6):1107-1133.

Lee, L. (2007). Identification and estimation of econometric models with group interactions, contextual factors and fixed effects. Journal of Econometrics, $140(2): 333-374$.

Manski, C. (1993). Identification of endogenous social effects: The reflection problem. Review of Economic Studies, pages 531-542.

Mill, J. S. (1984). Principles of Political Economy. Longmans, London.

Nickell, S. (1996). Competition and corporate performance. Journal of political economy, pages $724-746$.

Oberhofer, H. and Pfaffermayr, M. (2010). Firm growth in multinational corporate groups. Working Paper no. 2010-07, University of Salzburg. 
Penrose, E. T. (1959). The Theory of the Growth of the Firm. Basil Blackwell, Oxford.

Robson, P. and Obeng, B. (2008). The barriers to growth in Ghana. Small Business Economics, 30(4):385-403.

Salop, S. C. (1979). Strategic entry deterrence. American Economic Review Papers and Proceedings, 69(2):335-338.

Schumpeter, J. (1942). Capitalism, Socialism and Democracy. Harper: New York.

Shapiro, C. (1989). The theory of business strategy. Rand Journal of Economics, 20(1):125-137.

Silverman, B. (1981). Using kernel density estimates to investigate multimodality. Journal of the Royal Statistical Society. Series B (Methodological), 43(1):97-99.

Soetevent, A. (2006). Empirics of the Identification of Social Interactions; An Evaluation of the Approaches and Their Results. Journal of Economic Surveys, 20(2):193-228.

Storey, D. (1994). Understanding the small business sector. Thomson, London, UK.

Sutton, J. (1998). Technology and Market Structure: Theory and History. MIT Press, Cambridge, MA.

Sutton, J. (2007). Market share dynamics and the 'persistence of leadership' debate. American Economic Review, 97(1):222-241.

Teece, D., Rumelt, R., Dosi, G., and Winter, S. (1994). Understanding corporate coherence: Theory and evidence. Journal of Economic Behavior and Organization, 23(1):1-30.

Tornqvist, L., Vartia, P., and Vartia, Y. (1985). How should relative changes be measured? American Statistician, 39(1):43-46. 
Vickers, J. (1995). Concepts of competition. Oxford Economic Papers, 47(1):1-23.

Wiggins, R. and Ruefli, T. (2005). Schumpeter's ghost: Is hypercompetition making the best of times shorter? Strategic Management Journal, 26(10):887-911.

Wiklund, J. (2007). Small firm growth strategies. In Zackarakis, A. and Spinelli, S., editors, Entrepreneurship and growth: The engine of Growth (2nd edition), chapter 7, pages 135-154. Praeger: Westport, Connecticut. 